\title{
Room Automation System in Politeknik Sultan Abdul Halim Mu'adzam Shah (POLIMAS)
}

\author{
Nurolhuda Mohd Noor ${ }^{l}$, Nui Din Keraf ${ }^{1}$, Hafifah Darus ${ }^{l}$, Virakwan Hai Kelian ${ }^{2}$ and Phaklen Ehkan ${ }^{3}$ \\ ${ }^{1}$ Department of Electrical Engineering, Politeknik Sultan Abdul Halim Mu'adzam Shah, Kedah \\ ${ }^{2}$ Department of Information Technology and Communications, Politeknik Seberang Perai, Penang \\ ${ }^{3}$ School of Computer and Communication Engineering, Universiti Malaysia Perlis, Perlis
}

\begin{abstract}
The objective of this paper is to design an efficient room automation system in POLIMAS to control and automatize lighting, fan and air-condition.. This system will overcome human mistakes where the students or staffs forget to switch off the appliances in classroom or laboratories, and effectively reduce the cost of operation and power consumption of the buildings. Room Automation involves the automation and controlling the electrical appliances. The system will monitors electrical parameters of room appliance such as temperature, humidity and ambient light. The factors like temperature and light can have significant effects on the productivity of office workers as well as students. Thus, classrooms, laboratories and staff offices can be equipped with super sensors featuring temperature and light monitors. Besides, it helps in reducing power consumption by monitoring the environment condition and controlling the appliances as well as conservation of energy in the campus. Furthermore, it provides simple and cost effective to the institution. The system uses Arduino ESP8266 NodeMCU platform as the IoT enddevice connecting to various sensors and actuators to the platform via Wi-Fi channel. By using Wi-Fi connectivity, the hardware integrates with software application to control, monitoring and analysis. A sequence testing is conducted to determine the connectivity and integration of hardware and software. The performance of each sensor was performed to measure the accuracy. As a result, PIR sensors are able to detect general movement in effective range of about 10 meters. Moreover, the DHT temperature sensor in range of 5 meters away from air-condition is able to read the present room temperature and send command to the air-condition adjusting the air- condition's set temperature similar to the air-condition's remote. Thus, by implementing this system, not only the electrical appliances in a room more manageable and under control but also able to reduce the operational cost and improve environmental protection.
\end{abstract}

\section{Key words: Internet of Thing (IoT), Room Automation, Sensors, Controller}

\section{Introduction}

The Internet of Thing (IoT) is a technology that integrated many objects of everyday life which equipped with microcontrollers, transceivers for digital communication, and suitable protocol stacks to interconnect with each other and the users [1]. Together with the growing and development of the educational institution in Malaysia, it is important for educational to become the pioneer in technology advancement and innovation, transferring knowledge and implement it into real environment. Based on the development of smart cities and IoT implementation, POLIMAS came out with the idea of Smart Digital Campus. The common goals of Smart Digital Campus implementations is to reduce energy consumption and power costs by using IoT platform to enhance sustainability in the campus. Therefore, room automation system has been proposed under this innovation.

The main idea of room automation system is to reduce the power consumption in POLIMAS campus as human can make mistakes and forget to switch off the appliances when not in used. Most of the time, the light, fan and air-condition in the classrooms, laboratories and staff offices are still in ON condition even no people inside. As a result, it has a direct impact on the cost of operation and power consumption of the buildings. According to Muhammad, A. and Ahsan R, [2], the cause of increasing in energy consumption is that people inability to access and control the appliance remotely. Recently, the energy is wasted by modern people as they do not care much about energy so they use it according to their comfort. Akshai M. S. et al. in

Corresponding Author: Nurolhuda Mohd Noor, Department of Electrical Engineering, Politeknik Sultan Abdul Halim Mu'adzam Shah, Kedah 0194334628, nurol.mas@gmail.com 
2017 mentioned that people should be aware of the importance of energy savings since energy is the most important aspect in every one's life. For Academic Campus such as POLIMAS, there is the best place to adopting and educating the students as well as staffs regarding the importance of energy saving.

The concept of room automation system include three main components namely, an Android application to control electrical appliances, Wi-Fi for signal transfer and an Arduino controller for controlling the switch of the appliances. The commands from Android application are sent via Wi-Fi to Arduino platform. The systems include the control and automation of light, fan and aircondition functioning in the room. It is focused on the development of real prototype consists of Arduino as a hardware platform and Android as a software platform. Hardware is the integration of Arduino and various sensors for detection. The sensors include PIR (Passive Infrared) sensor used to turn $\mathrm{ON}$ and $\mathrm{OFF}$ the lighting and fan system automatically by detecting the presence of human while DHT sensor used for automatic temperature control by read the present temperature of the room and make the adjustment to maintain the temperature automatically. This method can avoid the aircondition to work for lower temperature values for a long time and thus making it consume less power. The hardware part will connect to the software through the Wi-Fi access.

Many challenges must be considered in order to design an efficient room automation system by using the IoT concept. According to Abuarqoub et al. [4], most of the existing approaches IoT suffer from inherent problems that limit their applications. Firstly, since the controlling and monitoring operations are based on the Wi-Fi interconnect, it is difficult to maintain the $\mathrm{Wi}-\mathrm{Fi}$ range and connectivity in POLIMAS campus. Secondly, the collaborative of various devices and sensing into a single system may present an enormous burden to configure manually. Indeed, new ways of the automated configuration of IoT devices are needed to be thoroughly investigated. Thirdly, it is a large number of smart objects collaborated with each other to provide information about the surroundings, thus, an enormously huge volumes of data would be generated. Handling such big sensory data poses a major challenge as it requires advanced data fusion and optimization techniques. Since the data processing is to be performed in real-time, high speed communication links and powerful processing units is needed. Finally, another important challenge of room automation system is the power supply and energy efficiency to perform the controlling and automation operations.

\subsection{Aims and Objectives}

The main objective of this work is to design a room automation system that automatically controlling electrical appliance in the classrooms, laboratories and staff offices. Additionally, this system aims to assist human by automatically and controlling the electrical appliances once the human enter the room as the first step to this system. To achieve the main objective, there are some specific objectives need to be done and these include

1) To develop the prototype of POLIMAS room automation system with IoT implementation.

2) To simulate the functionality of the room automation system.

3) To innovate the system with better improvement of automatically and controlling the electrical appliances.

\subsection{Scope of Work}

The scope of this research is to assist human automatically and controlling the electrical appliances in a room. The electrical is controlled by Wi-Fi, sensors and relays. To switch ON or OFF the light, Wi-Fi is connected to Arduino will send commands to Arduino platform. Another sensor is used to automatically control temperature by reads the present temperature in the room and makes the adjustment to maintain the temperature level. All the output data and activities from this system will be captured and managed properly through available cloud. As a result, all of the data can be used by campus operations teams to pursue the common goals of IoT implementations.

\section{Methodology}

The room automation system is separated into two features; hardware and software configurations. Figure 1 shows the design of the room automation system.

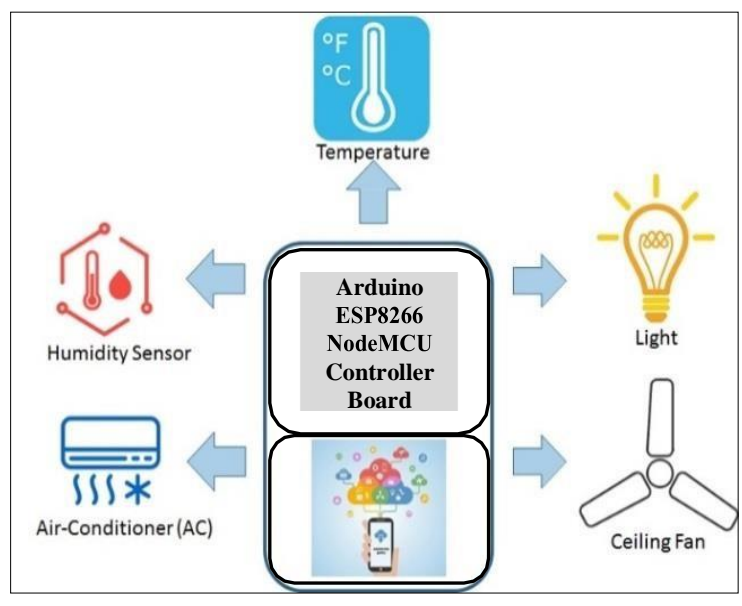

Figure 1: Room Automation System Design 
Hardware configuration is the combination of a prototype and an Arduino ESP8266 NodeMCU controller board. The hardware is integrated with a second approach is integrating Arduino ESP8266 NodeMCU controller with the relay and connect to the electrical appliances switch as a prototype and software. Software configuration is the method used to control the electrical appliance remotely.

\subsection{Hardware Configuration}

This is done by using an ESP8266 Wi-Fi module with NodeMCU firmware integrate with PIR sensor for automatic lighting and fan application. DHT sensor is used for monitoring and controlling the temperature and humidity. Figure 2 shows the block diagram of hardware platform which consists of Arduino ESP8266 module, PIR sensor, DHT Sensor, Relay and power supply.

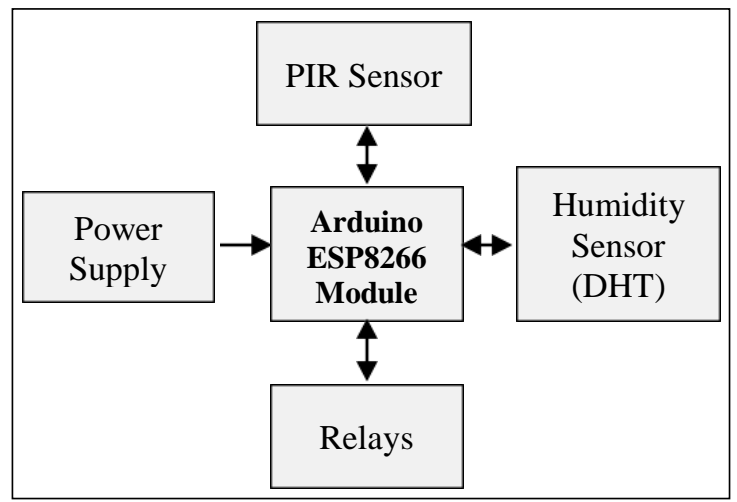

Figure 2: Block Diagram of Hardware Platform

Arduino ESP8266 module using NodeMCU is a low cost $\mathrm{Wi}-\mathrm{Fi}$ microchip incorporating both a full TCP/IP stack and microcontroller capability [5]. The PIR-based motion sensor sends a signal to relay and switch on lights when a person is in the room. PIR sensor has a sensor face that measures different air temperatures in a room. It is an electronic sensor that measures infrared (IR) light radiating from objects in its field of view. According to Nabirul, I., Kazi, T., R., Shamima, I., N. [6], PIR sensor is a simplest type that vastly used as occupancy sensor for its inexpensiveness and better usage. PIR sensor is a compact size (28 X $38 \mathrm{~mm})$, less complex, easy to install, power consumption very low (current drain $1.5 \mathrm{~mA}-0.1 \mathrm{~mA}$ and $\mathrm{DC}$ $0.8 \mathrm{~V}-405 \mathrm{~V})$, high sensitivity, low noise, delay time can be varied from $5 \mathrm{~s}$ to 18 minutes. Therefore, PIR sensor has chosen to use in this project. The PIR motion sensors are used to control lights, turn them off periodically when there is no movement in the room. This motion sensor send the input to relay, to shut off power if it does not detect any motion within specific duration. In other words, the room automatically cut off power when it is empty. programme, written in $\mathrm{C}++$ programming language. Two different approaches are carried out in this project. The first approach is connecting the software directly to the Arduino ESP8266 NodeMCU controller board to ensure that simulation could work. Once it successfully carried out, the Furthermore, temperature sensor (DHT) which reads the present temperature of the room and based on that value it will send commands to the air- condition through an IR blaster similar to the function of aircondition's remote. The air condition will react to these commands as if it is reacting to its remote and thus adjust the temperature. The Arduino ESP8266 NodeMCU controller will also adjust the air condition's set temperature to maintain the temperature level. The sensor DHT is an analog sensor designed to sense the physical change in heat and moisture when exposed in air with suitable wiring and programming. The use of DHT11 sensor has shown its usefulness measuring and controlling temperature and humidity in home appliances, medical and many other sectors [7].

Further, relay is used to connect to the light and fan switches, based on input from PIR sensor. According to Akshai M. S. et al., [3], relays are used wherever it is necessary to control a high power or high voltage circuit with a low power circuit. Figure 3 shows the circuit diagram of NodeMCU connect to the relay.

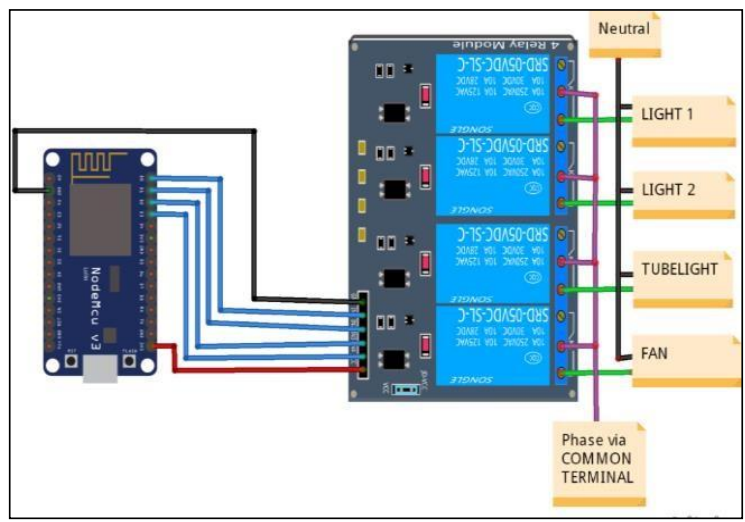

Figure 3: Circuit Diagram of Relay and NodeMCU Connectivity

Relay is a digital switch that controls much higher currents and voltages. This device is widely used in power protection. The benefits of this device are small in size, stability and long-time reliable and it can be also used for both ac and dc systems Pathan, et. al [8]. Finally, when all the connections and wiring are done, the code are written in integrated development environment (IDE) tool and the codes written in IDE tells the Arduino ESP8266 module to function so that the measurement can be obtained from the sensors. When the codes are successfully loaded into the Arduino ESP8266 module, next approaches is integrating it with the relays and connect to the electrical appliance switches as a prototype. As first time 
implementation, this prototype installed at the UPIK room for testing and monitoring. The relay connected to the light switches, fan switches and air condition power unit.

\subsection{Software Configuration}

\section{Software configuration}

including development of

application is using Android Studio to access control mechanism. Referring to Mowad et. al [9], Android is used in a number of development projects with concept of smart cities; it was the platform of choice for user end device development included APIs using PHP scripts to access the web for retrieval storage of data in a web based database. Thus Wi-Fi connectivity is required for the application to work. Further MySQL database connectivity was used for the specific purpose of data management. Figure 4 shows the user interface of the mobile application on smart phone. The main menu of the application is consists of user login by enter the username and password for the security purpose.

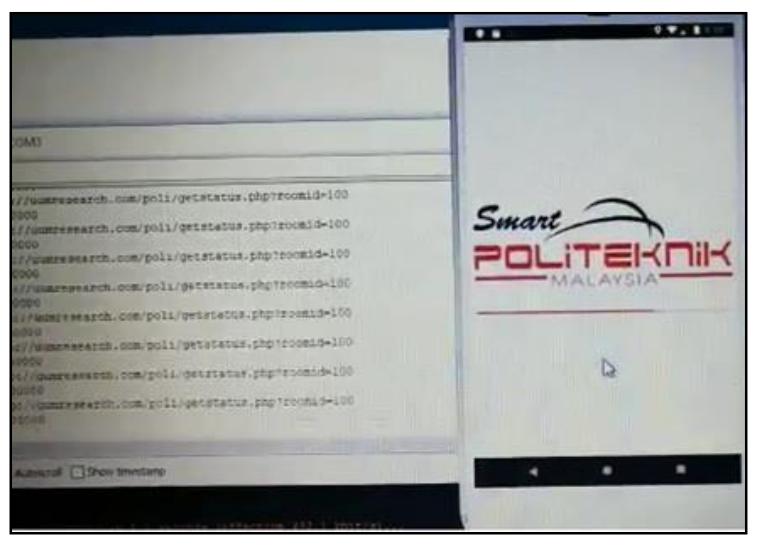

Figure 4: User Interface of the Mobile Application on Smart Phone

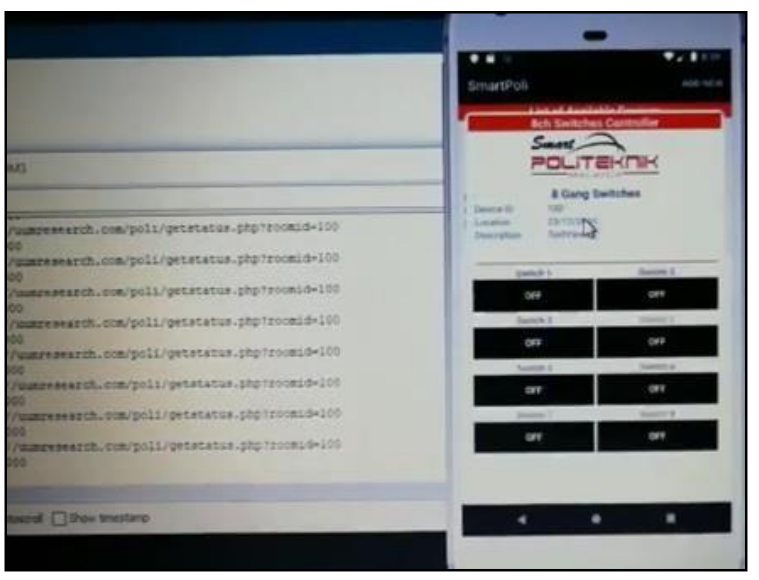

Figure 5: Control Panel Interface on Smart Phone
The mobile application will connect to the Arduino ESP8266 NodeMCU controller for controlling the appliances. Figure 5 shows the control panel interface on smart phone that consists of $\mathrm{ON}$ and OFF buttons to control the lights, fans and air condition. Wi-Fi is used as an interconnected media between Arduino platform and android application. Figure 6 shows the integration of hardware and software block diagram. With the established connection, the room should behave rationally and able to be controlled from an android mobile application.

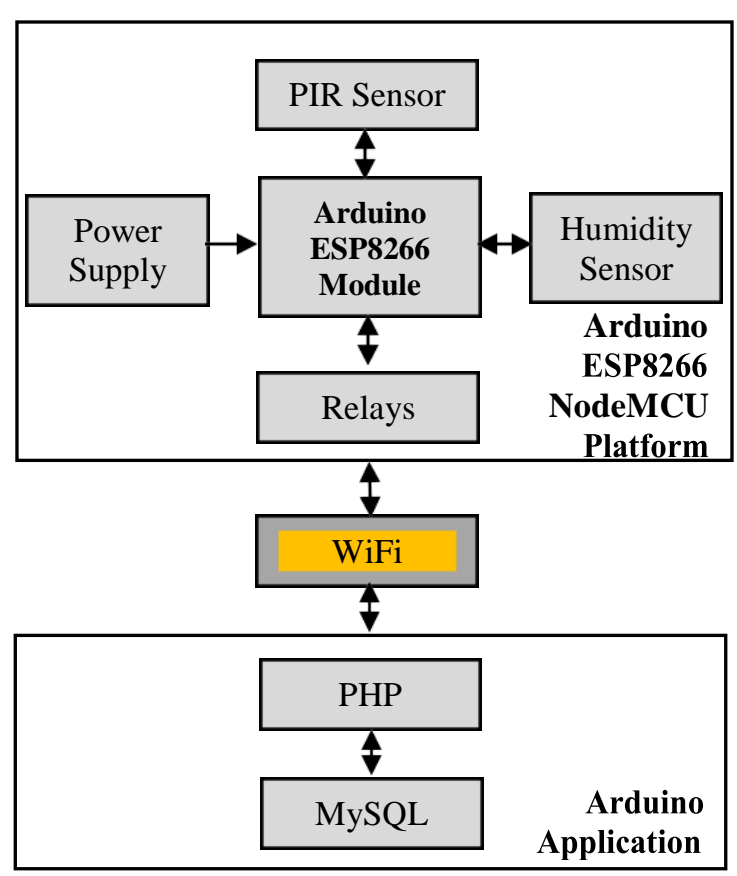

Figure 6: Block Diagram of Integration Hardware and Software Platform

\section{Result and Discussion}

First phase of the system evaluation will be discussed in this section. First phase is to perform unit testing, component testing and integrated testing include the ability of the system to function automatically and controlling the electrical appliances in Unit Penyelidikan Inovasi dan Komersil (UPIK) room. According to Basen J., [10] the first level of testing a new system is to validate that the system satisfies the clients' goals. Unit testing performed by checking the code for every functions and class. The results shows there is no error or bug when running the code. In component testing, all the components including electrical 
appliances, motion, temperature and humidity are test individually. Referring to Castro, J., Psota, J., [11], it is easy to spot the bugs, locate and fix if each module individually test. After the testing, finds that all the components and tasks perfectly working.

For the integration testing, end-to-end testing is done to verify the integration of software and hardware. Table 1 displays the integration testing result and it can be seen that all the

Table 1 : Result of Intergration Testing

\begin{tabular}{|l|c|c|c|}
\hline \multicolumn{1}{|c|}{$\begin{array}{c}\text { Test } \\
\text { Description }\end{array}$} & $\begin{array}{c}\text { Expected } \\
\text { Result }\end{array}$ & $\begin{array}{c}\text { Observed } \\
\text { Result }\end{array}$ & $\begin{array}{c}\text { Test } \\
\text { Result }\end{array}$ \\
\hline $\begin{array}{l}\text { User } \\
\text { successfully } \\
\text { login into the } \\
\text { system }\end{array}$ & $\begin{array}{c}\text { Successful } \\
\text { login }\end{array}$ & $\begin{array}{c}\text { Successfully } \\
\text { login }\end{array}$ & Pass \\
\hline $\begin{array}{l}\text { User can easily } \\
\text { access the } \\
\text { room appliance } \\
\text { switch }\end{array}$ & $\begin{array}{c}\text { Accessible } \\
\text { every } \\
\text { switches }\end{array}$ & $\begin{array}{c}\text { Easily } \\
\text { accessible }\end{array}$ & Pass \\
\hline $\begin{array}{l}\text { User can } \\
\text { control the } \\
\text { electrical } \\
\text { appliance }\end{array}$ & $\begin{array}{c}\text { Easily } \\
\text { controllable }\end{array}$ & $\begin{array}{c}\text { User } \\
\text { controlled }\end{array}$ & Pass \\
\hline
\end{tabular}

Moreover, the air condition's temperature is under controlled based on the setting level of room temperature according to the DHT sensor that senses the changes of temperature and humidity levels. The overall results show that the performance of the system was accurately functioning and reliable in use.

\section{Conclusion}

The operation of room automation system was analyzed in this paper. The objectives which had been proposed in this project have been achieved. The system is able to control and automate the electrical appliances effectively in the proposed room. This room automation system has the interconnections between electrical appliances and sensors for controlling and automation. The development of mobile application (Apps) is easy to be used and installed. Any Android based Smart phone with built in support for Wi-Fi can be used to access and control the appliances in the room. It can be clearly seen that the development of this prototype impacts to social well-being and environmental sustainability by lowering the power consumption, costs and environmental protection. Automation of rooms helps in optimizing energy consumption and easy usage of room operations. Room automation system can be the real future to be implemented in POLIMAS green campus because it can be energy saving for the future. requirements has been achieved. The testing also included the testing of system ON and OFF of room lights and fan automatically by detecting the human presence in the room. As a finding, there is no need to press the switches panel every time when person enters the room. The appliances will automatically switch ON when detecting the human movement and switch OFF when there is none of any human movement within the sensor range and time delay set.

\section{Limitation and Recommendation}

Besides all the advantages of the development of room automation system, there are also some limitations. The system is fully based on the $\mathrm{Wi}-\mathrm{Fi}$ connectivity. This system is unable to be controlled if Wi-Fi is not available or not in the good bandwidth. As a recommendation for the future work, system with other alternatives or backup of connectivity is included in the system.

\section{Acknowledgement}

This project was financially supported by the TVET-ARGS (T_ARGS - 91001418) scheme under the Ministry of Education, Malaysia.

\section{References}

[1] Luigi Atzori, Antonio Lera, Giacomo Morabito (2010). The Internet of Things: A survey. Computer Networks, 54 (15), 2787-2805.

[3] Akshai M. S., Christo C. J., Jayakrishnan A. P., Nijo S.T., Midhun V., Reshma K.R., (2017). Automated Smart Room. International Journal of Advances in Engineering \& Scientific Research, 4 (1), 2349 -3607.

[2] Muhammad, A., Ahsan, R. (2016). An Overview of Home Automation Systems. $2^{\text {nd. International }}$ Conference on Robotics and Artificial Intelligence (ICRAI). 27-31.

[4] Abuarqoub, A., Abusaimeh, H., Hammoudeh, M., Uliyan, D., Abu-Hashem, M., Murad, S., AlJarrah, M., Al-Fayez, F. (2017). A Survey On Internet of Things Enabled Smart Campus Applications. Proceedings of the International Conference on Future Networks and Distributed Systems (50).

[5] Al-Dahoud, A., Fezari, M. (2018). NodeMCU V3 For Fast IoT Application

Development. Faculty of IT, Al-Zaytoonah University Amman.

[6] Nabirul, I., Kazi, T., R., Shamima, I., N. (2013). Smart Departmental Store. B. Sc. in EEE thesis submitted to the Dept. of Electrical \& Electronic 
Engineering. BRAC University.

[7] Anon., 2017. ArduinoUnoRev3. Store

Arduino.

Retrieved from: https://store.arduino.cc/arduino -uno-rev3.

[8] Pathan, H., S., A., Shaikh, S., S., Shaikh, G. (2018). Automatic Gadget Control System Using Arduino and PIR Sensor. International Journal of Management, Technology and Engineering. 8(XI), 458-464.

[9] Mohamed, A., ELatif, M., Ahmed, F., Ahmed H. (2014). Smart Home Automated Control System Using Android Application and
Microcontroller. International Journal of Scientific \& Engineering Research, 5(5), 935939.

[10] Basen, J. (2018). Control \& Automation: How to Test a Home-Automation System (the Professional Way). Cepro. Retrieved from: https://www.cepro.com/article/how_to_test_a_h ome_automation_system.

[11] Castro, J., and Psota, J., (2018). The Specification, Design, and Implementation of a Home Automation System. Introductory Digital Systems Laboratory Final Project. Massachusetts Institute of Technology. 
